\title{
BMJ Open Cohort profile: the Canadian coordination and activity tracking in children (CATCH) longitudinal cohort
}

\author{
John Cairney, ${ }^{1}$ Scott Veldhuizen, ${ }^{2}$ M Christine Rodriguez, ${ }^{1}$ Sara King-Dowling, ${ }^{3}$ \\ Matthew Y Kwan, ${ }^{4}$ Terrance Wade, ${ }^{\circ 5}$ David Price, ${ }^{4}$ Cheryl Missiuna, ${ }^{6}$ \\ Brian Timmons ${ }^{3}$
}

To cite: Cairney J, Veldhuizen S, Rodriguez MC, et al. Cohort profile: the Canadian coordination and activity tracking in children (CATCH) longitudinal cohort. BMJ Open 2019:9:e029784. doi:10.1136/ bmjopen-2019-029784

- Prepublication history for this paper is available online. To view these files please visit the journal online (http://dx.doi org/10.1136/bmjopen-2019029784).

Received 11 February 2019 Revised 11 July 2019 Accepted 22 July 2019

Check for updates

(C) Author(s) (or their employer(s)) 2019. Re-use permitted under CC BY-NC. No commercial re-use. See rights and permissions. Published by BMJ.

${ }^{1}$ Faculty of Kinesiology and Physical Education, University of Toronto, Toronto, Ontario,

Canada

${ }^{2}$ Infant and Child Health Lab, McMaster University, Hamilton, Ontario, Canada

${ }^{3}$ Department of Pediatrics, McMaster University, Hamilton, Ontario, Canada

${ }^{4}$ Department of Family Medicine McMaster University, Hamilton, Ontario, Canada

${ }^{5}$ Faculty of Applied Health Sciences, Brock University, St. Catharines, Ontario, Canada

${ }^{6}$ School of Rehabilitation Science, McMaster University, Hamilton, Ontario, Canada

Correspondence to

Dr John Cairney;

john.cairney@utoronto.ca

\section{ABSTRACT}

Purpose Developmental coordination disorder (DCD) is a prevalent, neurodevelopmental disorder affecting $2 \%$ to $5 \%$ of children, which is characterised by fine and gross motor problems. Children with DCD have been shown to be less fit and physically active than other children; however, the direction of causality is unknown as previous studies have typically been done in older children when the differences in fitness and physical activity are already present. The aim of the Coordination and Activity Tracking in Children (CATCH) study is to specifically address the issue of precedence by recruiting a large sample of children in early childhood.

Participants CATCH comprises a community-based sample of parents and children 4 to 5 years of age divided into two groups: at risk for DCD ( $\mathrm{rDCD} ; \mathrm{n}=287)$ and typically developing (TD; $n=301$ ). Inclusion in the rDCD group required a score at or below the $16^{\text {th }}$ percentile on a standardised test of motor coordination and a score above 70 on a standardised test of intelligence.

Findings to date Children in the rDCD group contained a higher proportion of males $\left(67 \%\right.$ vs $48 \%, \chi^{2}=21.9$, $\mathrm{p}<0.001)$. Children in the rDCD group had lower mean IQs, aerobic and musculoskeletal fitness than children in the TD group ( $p<0.001$ for all). There were no differences observed between groups for body composition or physical activity. Parent characteristics did not differ, with one exception: partners of reporting parents of rDCD children were less likely to hold a university degree (44\% vs $57 \%$ $\left.\chi^{2}=7.4, p=0.004\right)$. According to parent report, rDCD children experienced more problems in self-care, school and leisure activities $(p<0.001$ for all).

Future plans Children are being followed up annually for 3 years. At each follow-up, motor coordination testing is repeated, and data are collected on physical activity, fitness and social-emotional problems.

\section{INTRODUCTION}

Developmental coordination disorder or DCD is the preferred diagnostic label for children presenting with significant problems in motor coordination and related functional impairments. Affecting between 1.6\% and $5 \%$ of the paediatric population, ${ }^{1}$ DCD is common and also co-occurs with other neurodevelopmental disorders including

\section{Strengths and limitations of this study}

This is the largest cohort study to date of preschool aged children with low motor coordination.

- This study collects data on a diverse range of factors, including fitness, participation in physical activity, diet, sociodemographic variables, health and risk factors for obesity, among others.

- Inclusion in the at risk for developmentalcoordination disorder group was based primarily on motor coordination scores, but other Diagnostic and Statistical Manual of Mental Disorders, Fifth Edition and European Academy of Childhood Disability criteria were also collected.

- One limitation is that the sample is fairly homogenous; parents are generally white, native English speakers with relatively high socioeconomic status.

attention-deficit hyperactivity disorder $(\mathrm{ADHD})^{2}$ and autism spectrum disorders (ASD). ${ }^{3} 4$ The presentation of symptoms is varied, with children experiencing significant difficulties with fine and/or gross motor coordination. ${ }^{56}$ Although the aetiology of DCD is not yet known, risk factors include low birth weight and perinatal complications at birth. ${ }^{7}$ Most studies show that the disorder is more common in boys. ${ }^{8}$ Despite the relatively high prevalence of the condition, most children do not receive a diagnosis. ${ }^{9}$

Importantly, previous research has shown that DCD is also associated with a number of negative physical and mental health-related problems, including overweight/obesity, ${ }^{10}$ poor physical fitness, ${ }^{11} 12$ physical inactivity, ${ }^{13}$ poor self-esteem and perceived competence $^{1415}$ and increased risk of internalising problems. $^{2}{ }^{16}$ As each of these factors are themselves associated with a host of negative physical, mental and social outcomes later in life, children with DCD may be on a troubling trajectory, which, if not corrected, threatens their long-term health, development and quality of life. 
With regard to physical inactivity and health-related fitness in particular, previous research has consistently shown that children with DCD (poor motor coordination) are less active and less fit than their typically developing peers. ${ }^{101718}$ However, studies in this area have been able to offer little evidence on the direction of causality - whether poor motor coordination is the cause or effect of low fitness and hypo-activity. ${ }^{17}$ Although longitudinal studies have been conducted in this population, they have been unable to convincingly address questions of precedence, either because sample sizes were small or because the studies began relatively late in childhood ${ }^{10-21}$ when differences between groups in inactivity and fitness are already present. ${ }^{101921}$ In addition, the influence of psychiatric co-morbidity, especially ADHD, on physical inactivity and health-related fitness in this population is not well-understood.

To address this gap in the literature, we designed and implemented the Coordination and Activity Tracking in Childhood (CATCH) study. CATCH is a 4 year longitudinal study beginning in early childhood; it was designed to include 300 children with poor motor coordination and 300 with functioning in the typical range. Participants are aged four or five at baseline, because this is the earliest age at which assessments of motor coordination are regarded as reasonably reliable, based on guidelines published at the time. ${ }^{1}$ At baseline, parents report on their child's medical history, level of motor coordination and psychiatric symptoms, and complete a demographic and socioeconomic survey, while repeated measures include direct assessments of the child's motor coordination, health-related fitness, physical activity and gait. While previous studies have sampled children with DCD under 6 years of age, ${ }^{22-26}$ CATCH is the first study to our knowledge designed specifically to track physical activity, health-related fitness and psychiatric comorbidity in children with and without poor motor coordination from early to middle childhood.

In this paper, we describe the recruitment, application of study inclusion and exclusion results and initial classification of children into groups based on their performance on a standardised motor assessment. We also present demographic, physical activity and health-related fitness data, as well as data relevant to the diagnosis of DCD: motor coordination, cognitive ability and impairments in activities of daily living. Differences in motor coordination, cognitive ability, difficulties with activities of daily living, physical activity, health-related fitness and general demographics are examined between groups.

\section{COHORT DESCRIPTION}

\section{Study design}

The CATCH study is a prospective case-control study with an initial target cohort of 600 children age 4 to 5 years at baseline. The sample size was calculated to permit detection of standardised differences of approximately 0.3 over four measurement periods, with $80 \%$ power, a significance level of 0.05 , and $10 \%$ annual attrition. Children attend yearly visits for 3 years, resulting in a total of four visits (including baseline). At each visit, children complete a motor coordination assessment, intelligence test, anthropometric assessments and battery of non-invasive physical fitness measures. Physical activity is measured objectively with accelerometers for 7 days following each assessment. Parents provide additional information about their child's performance of daily activities, demographics, measures of health and risk factors for obesity and measures of participation in physical activity through a parental interview and various surveys. The Hamilton Integrated Research Ethics Board provided ethical approval for the study. Details of the study protocol have been previously published. ${ }^{27}$

\section{Identifying children at risk for DCD}

Children were considered to be at risk for DCD (rDCD) based in part on the Diagnostic and Statistical Manual of Mental Disorders, Fifth Edition (DSM-V) definition of DCD ${ }^{5}$ which includes the following criteria: if they had significant motor coordination deficits that significantly impair performance of activities of daily living (ADLs) or academic achievement, and that were not due to existing intellectual disability (IQ above 70) or neurological conditions affecting movement. Although ADLs were assessed in the present study, they were not used to define cases of rDCD.

\section{Measures}

Motor coordination

The Movement Assessment Battery for Children - Second Edition (MABC-2) was used to assess motor coordination and to identify children with rDCD based on established threshold cutpoints $\left(\leq 16^{\text {th }}\right.$ percentile). The MABC-2 is the most widely used assessment for the identification of DCD. ${ }^{1}$ It is an individually administered standardised test which includes eight motor tasks in three categories: Manual Dexterity, Aiming \& Catching and Balance (both static and dynamic). Raw scores on these items are converted into standard scores based on the child's chronological age, and then converted into an overall percentile. Test re-test reliability and standard of error of measurement for the standard test scores have been reported to be 0.80 and 1.34 (corresponding to 0.45 SDs), respectively. ${ }^{28}$ Studies have shown that the MABC-2 is a reliable and valid tool for the assessment of movement difficulties, including in very young children ( 3 to 6 years of age). ${ }^{28} 29$

\section{Intellectual ability}

Children completed the Kaufman Brief Intelligence Test Second Edition (KBIT-2) to evaluate intellectual ability. It is a quick (15 to $20 \mathrm{~min}$ to administer at this age) and reliable measure that requires no reading or writing and is suitable for children 4 years of age and older. ${ }^{30}$ The KBIT-2 measures function in two cognitive domains (verbal and non-verbal intelligence), and provides three standard 
scores: verbal, non-verbal and IQ composite. All standard scores have a mean of $100(S D=15)$ for the general population. The IQ composite measures general intelligence and is calculated from the verbal and non-verbal scores. Children with an IQ composite below 70 at baseline were re-administered the KBIT-2 at later appointments to ensure their result was not due to language delays or language barriers (ie, recent immigration to Canada).

\section{Performance of daily activities}

A parental semi-structured interview ("Listening for DCD") was developed to measure children's motor-related difficulties in active play, self-care and in school. This measure has been used successfully to confirm DCD in studies with children 4 years and older. ${ }^{31} 32$ For a child to be formally diagnosed with DCD, parents must report evidence of significant functional impact in at least one domain. ${ }^{5}$

\section{Demographic and health-related questionnaire}

Parents are asked to complete questions about family demographics, health, risk factors for obesity and participation in physical activity (theirs and their child's).

\section{Health-related fitness}

\section{Body composition}

Height and weight are measured without shoes and in light clothing using a stadiometer (SECA 264, Chino, California) and digital scale (SECA 869). Measurements are taken in duplicate and are repeated if the two measurements are $>0.1 \mathrm{~cm}$ or $>0.1 \mathrm{~kg}$ apart, respectively. The average of the two closest measures is used for height and weight, and to calculate body mass index (BMI; $\left.\mathrm{kg} \cdot \mathrm{m}^{-2}\right)$. BMI percentiles are determined based on the US Centers for Disease Control and Prevention growth charts. ${ }^{33}$

Waist circumference is measured to determine central adiposity by measuring midway between the top of the iliac crest and the lowest rib (as recommended by the WHO) ${ }^{34}$ Measures are taken against the skin during normal exhalation. Measurements are taken in duplicate and repeated if differences between measurements are $>0.5 \mathrm{~cm}$.

\section{Aerobic fitness}

Aerobic fitness is assessed using a progressive treadmill test, the Bruce protocol, where speed and grade increase every $3 \mathrm{~min}^{35}$ To ensure safety of the child, all children are required to hold onto the handrails throughout the duration of the test to assist with balance with a research assistant placed behind the child. At baseline, all children started the test at stage $1(1.7 \mathrm{mph}(2.7 \mathrm{~km} / \mathrm{h}), 10 \%$ grade). Heart rate is measured continuously throughout the test using a heart rate monitor (Polar H7, Kempele, Finland). The test is terminated when the child reaches exhaustion, is no longer able to keep up with the speed of the treadmill or refuses to continue despite verbal encouragement. Time on the treadmill is used as an indicator of aerobic fitness. Only children who reached a maximum heart rate $>180 \mathrm{bpm}$ are included in the analyses.

\section{Muscle strength and endurance}

Short-term muscle power is examined using a Wingate protocol $^{36}$ on a paediatric cycle ergometer (Lode pediatric; Lode BV, Groningen, the Netherlands). Children are asked to pedal as fast as possible against the internal resistance of the ergometer for approximately $20 \mathrm{~s}$. After a short rest, the Wingate test begins: children are instructed to pedal as fast as they can; once they reach $80 \%$ of their maximal pedalling cadence, a resistance relative to their body weight $\left(0.55 \mathrm{n} \cdot \mathrm{m} \cdot \mathrm{kg}^{-1}\right)$ is applied. The children pedal against this resistance for $30 \mathrm{~s}$. Mean power (W) is the average power output over the $30 \mathrm{~s}$ test and was calculated using the Lode Wingate software package (Lode $\mathrm{BV})$. Only children who continued to pedal throughout the entire duration of the test are included in the analysis.

\section{Physical activity}

Following their study visit, all children are asked to wear an accelerometer (Actigraph wGT3X, Pensacola, Florida) over their right hip for the following 7 days to assess their physical activity. Children are instructed to wear the accelerometer during all waking hours, only removing it for sleep and/or prolonged water activities. Parents are given a logbook to record the times the accelerometer was put on and removed. Non-wear periods are defined as any time the parent indicates the accelerometer was off and/ or $>60 \mathrm{~min}$ of consecutive zero counts. Only children who wore the accelerometer for at least three valid days ( $>10$ hour) are included in the analyses. Data are analysed in $3 \mathrm{~s}$ epochs, and Evenson cut points are applied to determine average daily minutes spent in moderate to vigorous physical activity (MVPA) ${ }^{37}$ The total time spent in MVPA is calculated for each valid day and then averaged across all valid days of wear. All accelerometer data are cleaned and processed using Actilife Software (Actigraph).

\section{Participants}

Parents were eligible if they could speak and read English and were the child's primary caregiver and legal guardian. Children were eligible to participate if they were 48 months, 0 days to 71 months, 30 days at their baseline appointment and could speak / understand English. There were two exclusion criteria: (1) any physical disability or diagnosed medical condition affecting motor coordination (eg, cerebral palsy) and (2) a birth weight of $1500 \mathrm{~g}$ or below. Extremely low birth weight children were excluded because they often present with comorbid health problems affecting motor coordination.

\section{Recruitment}

We recruited a community-based sample of participants from Hamilton, Ontario and surrounding areas using public school mail outs, community organisations (eg, Ontario Early Years Centres, Best Start programmes), community events targeting families and children, recruitment posters and social media. Families and children were recruited between October 2013 and June 2017, and testing began in February 2014. Parents who 


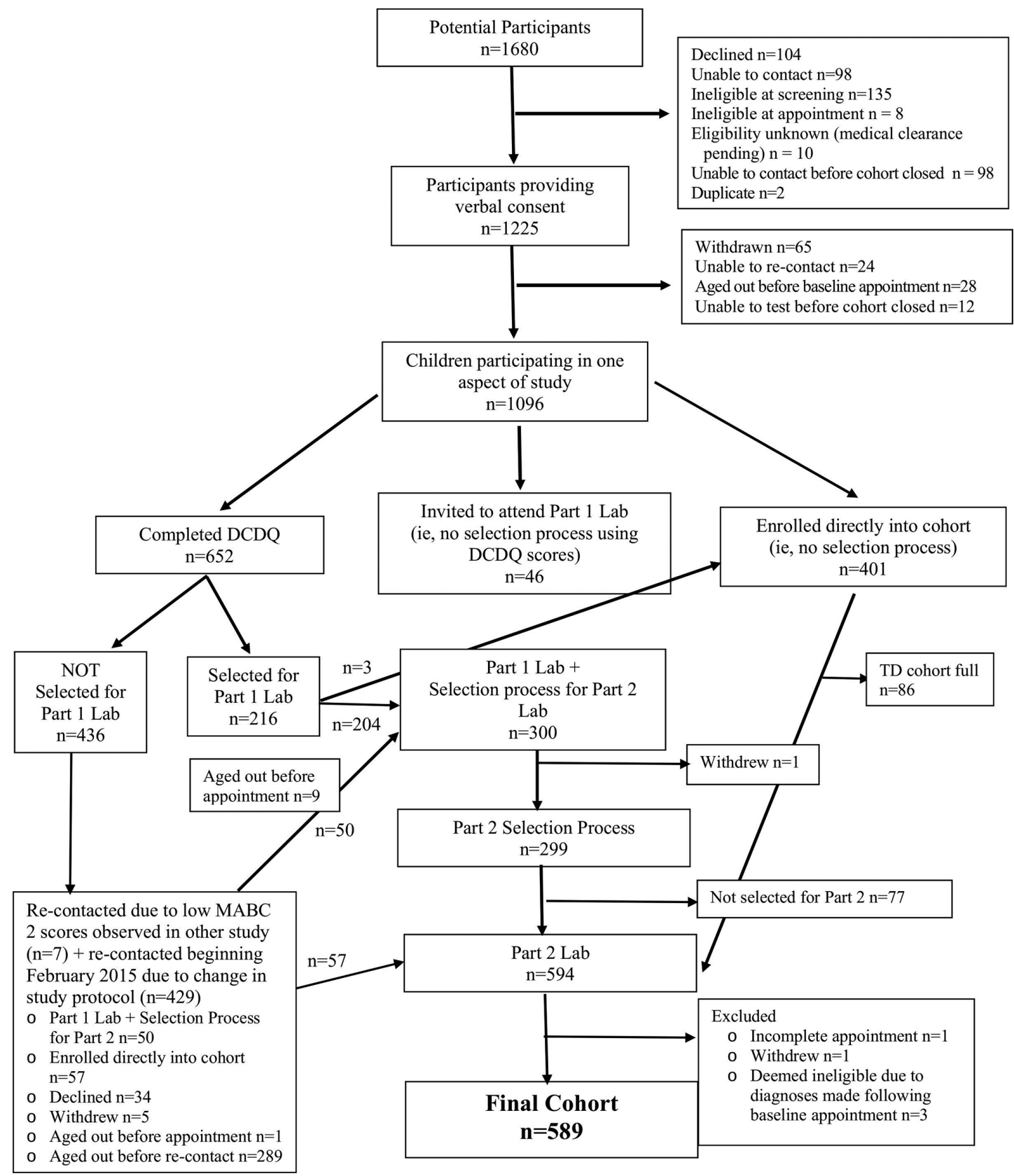

Figure 1 Participant flow. DCDQ, Developmental coordination disorder Questionnaire; MABC-2, Movement Assessment Battery for Children - Second Edition; TD, Typicallydeveloping.

contacted the study team directly or who provided their contact information via partnering community sites were provided with a study information package (via email or mail) and then telephoned by research staff to determine their child's eligibility and obtain informed, verbal consent.

CATCH used two methods of screening. From October 2013 to January 2015, participants' parents completed the Developmental Coordination Disorder Questionnaire (DCDQ) (figure 1), ${ }^{38}$ and all children who scored below 55 (out of 75) and a random sample of children who scored 55 or higher on this measure were invited to attend an appointment at the laboratory to complete baseline surveys and to have their motor coordination directly assessed using the MABC-2. This DCDQ threshold was selected by reanalysing previously collected data and identifying the level that offered the best cost-weighted tradeoff between sensitivity and specificity.

All children scoring at or below the $16^{\text {th }}$ percentile on the MABC-2 were recruited into the rDCD group of the longitudinal cohort, regardless of their DCDQ score. Children in the typically developing (TD) group of the longitudinal cohort included all children negative on both the MABC-2 and the DCDQ and a random sample of children with a positive DCDQ and negative MABC-2. Selection probabilities in the control group were calculated to produce a distribution of motor coordination representative of the general population (ie, with approximately 
the expected proportions at all levels). These probabilities were revisited and recalculated periodically based on study evidence of the DCDQ's true sensitivity and specificity in this context.

Early study results suggested that the prevalence of DCD based on the MABC-2 was higher than expected, at approximately $35 \%$ (compared with the expected prevalence of $16 \%$ based on the MABC-2 threshold), and that agreement between the $\mathrm{DCDQ}$ and MABC-2 was fair to poor, with an implied DCDQ sensitivity of approximately $45 \%$ and a specificity of $83 \%$. As a result, from February 2015 to May 2015, screening with the DCDQ was no longer implemented; instead, all children meeting the eligibility criteria were invited directly to the lab to complete the MABC-2. In addition, children who had been excluded from the laboratory visit based on their DCDQ score between October 2013 and January 2015 were re-contacted and also invited to the lab. Given this change, selection to the cohort also changed: children scoring $>16^{\text {th }}$ percentile were randomly assigned to the cohort with a $1 / 3$ probability and with no change, all children scoring $\leq 16^{\text {th }}$ percentile on the MABC-2 were selected for the cohort.

The recruitment and enrolment process was again re-visited in May 2015 due to a slower recruitment of TD children. Beginning in May 2015, all eligible children were enrolled into the cohort. Children were selected for both the rDCD and TD groups during all phases of recruitment until August 2016 when 301 children had been enrolled into the TD group. At this time, the TD cohort was closed to enrolment; only children scoring $\leq$ $16^{\text {th }}$ percentile on the MABC-2 at their baseline appointment were invited to the cohort.

Further details on the complete study protocol have been previously published. ${ }^{27}$

\section{Patient and public involvement}

This research was done without participant involvement. Participants were not invited to comment on the study design and were not consulted to develop relevant outcomes or interpret the results. Participants were not invited to contribute to the writing or editing of this document for readability or accuracy. We intend to disseminate the main results of the study to participants and will seek participant and public involvement in the development of an appropriate method of dissemination.

\section{Statistical analysis}

We divided children into two groups: children at risk for DCD (rDCD; at or below the $16^{\text {th }}$ percentile) and those who appeared to be 'typically developing' (TD; $>16^{\text {th }}$ percentile). We then produced descriptive statistics for motor coordination, intellectual ability (IQ), activities of daily living, demographic variables, physical fitness, body composition and physical activity, and tested for differences between groups. We used $\mathrm{X}^{2}$ tests and a t-test to test for differences in categorical demographic variables (table 1). Given the sex difference between the groups, we tested differences in remaining variables (tables 2 and 3) by fitting regression models with age and sex as covariates. For continuous variables, we used linear regression. For ADL difficulties, we used logistic regression, regressing group membership on a dummy-coded ADL variable, age and sex. In the latter case, our $p$ values reflect a postestimation contrast capturing the overall significance of the ADL item response indicators. All analyses were conducted using Stata V.14.

\section{Findings to date}

Figure 1 shows the stages of recruitment and participant exclusions. Overall, 1680 children were screened. Of eligible children whose parents provided verbal consent $(n=1225), 1096$ completed at least one component of the study: 758 children were assessed at the laboratory, with 594 of these children recruited into the cohort, and final data are available for 589 (see figure 1 for details): 301 TD and $288 \mathrm{rDCD}$.

Ten children were excluded due to a medical condition (Down syndrome, $\mathrm{n}=2$; autism spectrum disorder, with inability to understand/follow instructions, $n=2$; cystic fibrosis, $\mathrm{n}=1$; thalassaemia, $\mathrm{n}=1$; cerebral palsy, $\mathrm{n}=1$; congenital hypothyroidism, $\mathrm{n}=1$; birth defect (one born without a fibula, one with agenesis of corpus callosum), $\mathrm{n}=2$ ). A further 12 children were excluded due to medical conditions which raised concerns about maximal exercise testing, including tetralogy of Fallot, aortic stenosis, Wolf-Parkinsons-White syndrome and recent treatment for leukaemia. For these cases, we consulted a physician (DP) to determine if the child should be excluded from the study for safety reasons.

The KBIT-2 was re-administered to six of the seven children with an IQ score below 70 at baseline; all six had a standard score above 70 when re-assessed at later appointments. It was not possible to re-administer the KBIT-2 in one child, who was, thus, excluded from these analyses (thus, total $\mathrm{n}=588$ ).

To evaluate how the change to the sample recruitment process (ie, elimination of the DCDQ as a screener) may have affected the composition of the final sample, we compared MABC-2 scores in children in the rDCD group who were recruited using both the DCDQ screen and MABC-2 assessment versus children who were recruited solely on the basis of the MABC-2 assessment. This showed that $\mathrm{rDCD}$ children recruited using both the DCDQ screen and MABC-2 assessment had modestly poorer motor functioning than others (mean percentile $=7.8$ vs 9.8 ). As a result, the sample as a whole may be very slightly lower functioning than would be expected if the MABC-2 were used alone.

Child and parent demographics are presented in table 1, clinical variables in table 2 and child health-related fitness and physical activity in table 3. The rDCD group was slightly but significantly younger than the TD group and contained a higher proportion of males. Parent characteristics did not differ significantly between groups for marital status, household income, primary language 
Table 1 Group differences in demographic characteristics

\begin{tabular}{|c|c|c|c|c|}
\hline & TD & rDCD & Total & $P$ value \\
\hline \multicolumn{5}{|c|}{ Participant characteristics } \\
\hline Age & $5.0(0.6 ; n=301)$ & $4.9(0.6 ; n=287)$ & $5.0(0.6 ; n=588)$ & 0.01 \\
\hline \multicolumn{5}{|l|}{$\operatorname{Sex}(n(\%))$} \\
\hline Male & $145(48 \%)$ & $193(67 \%)$ & $338(57 \%)$ & $<0.001$ \\
\hline Female & $156(52 \%)$ & $94(33 \%)$ & $250(43 \%)$ & \\
\hline \multicolumn{5}{|c|}{ PMK characteristics } \\
\hline Age & $37.9(5.1 ; n=294)$ & $37.3(5.5 ; n=283)$ & $37.6(5.3 ; n=577)$ & 0.17 \\
\hline \multicolumn{5}{|c|}{ Birth mother (n(\%)) } \\
\hline No & $42(14 \%)$ & $30(10 \%)$ & $72(12 \%)$ & 0.20 \\
\hline Yes & $259(86 \%)$ & $256(90 \%)$ & $515(88 \%)$ & \\
\hline \multicolumn{5}{|c|}{ Married/common-law (n(\%)) } \\
\hline No & $27(9 \%)$ & $23(8 \%)$ & $50(9 \%)$ & 0.70 \\
\hline Yes & $274(91 \%)$ & $262(92 \%)$ & $536(91 \%)$ & \\
\hline \multicolumn{5}{|c|}{ Bachelor's degree or higher $(n(\%))$} \\
\hline No & $103(35 \%)$ & $113(40 \%)$ & $216(37 \%)$ & 0.18 \\
\hline Yes & $195(65 \%)$ & $170(60 \%)$ & 365 (63\%) & \\
\hline \multicolumn{5}{|c|}{ Bachelor's degree or higher (partner) $(n(\%))$} \\
\hline No & $117(43 \%)$ & $145(56 \%)$ & 262 (49\%) & 0.004 \\
\hline Yes & $154(57 \%)$ & $116(44 \%)$ & $270(51 \%)$ & \\
\hline \multicolumn{5}{|c|}{ Household income $>\$ 50000(n(\%))$} \\
\hline No & $33(11 \%)$ & $41(14 \%)$ & $74(13 \%)$ & 0.23 \\
\hline Yes & 263 (89\%) & $242(86 \%)$ & 505 (87\%) & \\
\hline \multicolumn{5}{|c|}{ Primary language English ( $\mathrm{n}(\%))$} \\
\hline No & 37 (13\%) & $39(14 \%)$ & $76(13 \%)$ & 0.67 \\
\hline Yes & $259(88 \%)$ & $246(86 \%)$ & $505(87 \%)$ & \\
\hline \multicolumn{5}{|c|}{ White $(n(\%))$} \\
\hline No & $66(22 \%)$ & $52(18 \%)$ & $118(20 \%)$ & 0.25 \\
\hline Yes & 235 (78\%) & $235(82 \%)$ & $470(80 \%)$ & \\
\hline
\end{tabular}

DCD, Developmental coordination disorder; PMK, Person most knowledgeable; rDCD, At risk for DCD; TD, Typically developing.

or ethnicity. However, a difference between groups was observed with education: partners of reporting parents of rDCD children were somewhat less likely to hold a university degree.

Parents of rDCD children were much more likely to report that their child had experienced problems in selfcare, school or leisure. Mean child IQs were also significantly lower in this group, although means for both groups remained within the average intelligence range.

There were no differences observed between groups for BMI percentile or physical activity. Children in the rDCD group had significantly lower aerobic and musculoskeletal fitness, and larger waist circumferences (see table 3).

\section{Strengths and limitations}

Using a community-based study design targeting recruitment of children 4 and 5 years of age, we were able to recruit a large sample of children, approximately half of whom appear to be at risk for DCD based primarily on their MABC-2 scores, but also secondarily on other characteristics collected after initial recruitment into the cohort. According to DSM-V $\mathrm{V}^{5}$ and European Academy for Childhood Disability (EACD) guidelines, ${ }^{1}$ in addition to scoring in the clinical range on a standardised test of motor coordination, in order to receive a formal DCD diagnosis there must be evidence of impairment in activities of daily living and/or scholastic performance, motor coordination difficulties must be present in early childhood and the motor coordination difficulties must not be better explained by a pre-existing diagnosis of neurological or other medical condition. The EACD guidelines also caution against a diagnosis of DCD when a child's IQ is below 70 .

Although on average, these characteristics are consistent with clinical criteria, caution is warranted. According 
Table 2 Group differences in Movement Assessment Battery for Children - Second edition (MABC-2) scales, intellectual ability and activities of daily living (ADL)

\begin{tabular}{|c|c|c|c|c|c|}
\hline & TD & rDCD & Total & $\begin{array}{l}\text { Adjusted group } \\
\text { difference }(95 \% \mathrm{Cl})^{*}\end{array}$ & $\mathbf{P}$ value \\
\hline \multicolumn{6}{|c|}{ MABC-2 percentiles and standard scoresł } \\
\hline Manual dexterity & $60.6(24.4 ; n=301)$ & $21.2(18.5 ; n=287)$ & 41.3 (29.3; n=588) & $-37.9(-41.5$ to -34.4$)$ & \\
\hline Aiming \& catching & $50.4(25.7 ; n=301)$ & $25.2(20.8 ; n=287)$ & $38.1(26.6 ; n=588)$ & $-25.2(-29$ to -21.4$)$ & \\
\hline Balance & $53.6(28.3 ; n=301)$ & 12.4 (11.6; n=286) & $33.5(30 ; n=587)$ & $-39.9(-43.5$ to -36.3$)$ & \\
\hline Total & $56.2(23.4 ; n=301)$ & $9.1(5.5 ; n=286)$ & $33.3(29.1 ; n=587)$ & $-45.9(-48.7$ to -43.1$)$ & \\
\hline \multicolumn{6}{|l|}{ K-BIT§ } \\
\hline Verbal IQ & $110.5(10 ; n=301)$ & $104.6(13.5 ; n=287)$ & $107.6(12.2 ; n=588)$ & $-5.7(-7.6$ to -3.7$)$ & $<0.001$ \\
\hline Non-verbal IQ & $99.5(13.1 ; n=301)$ & $96.4(12.2 ; n=287)$ & $98(12.8 ; n=588)$ & $-3.2(-5.3$ to -1.1$)$ & $<0.001$ \\
\hline Total IQ & $106.1(11 ; n=301)$ & $100.9(12.2 ; n=287)$ & $103.6(11.9 ; n=588)$ & $-5.2(-7.1$ to -3.3$)$ & $<0.001$ \\
\hline \multicolumn{6}{|c|}{ ADL difficulties $(n(\%))$ | } \\
\hline \multicolumn{6}{|c|}{ Self-care } \\
\hline No problems & $254(84 \%)$ & 195 (68\%) & $449(76 \%)$ & & $<0.001$ \\
\hline Uncertain $^{* *}$ & $23(8 \%)$ & $67(23 \%)$ & $90(15 \%)$ & 1.2 (0.7 to 2.2$)$ & \\
\hline Problems & $24(8 \%)$ & $25(9 \%)$ & $49(8 \%)$ & 3.4 (2 to 5.7$)$ & \\
\hline \multicolumn{6}{|l|}{ School } \\
\hline No problems & 280 (93\%) & $221(77 \%)$ & 501 (85\%) & & $<0.001$ \\
\hline Uncertain ${ }^{\star \star}$ & $6(2 \%)$ & 40 (14\%) & $46(8 \%)$ & 1.7 (0.8 to 3.3 ) & \\
\hline Problems & 15 (5\%) & 26 (9\%) & $41(7 \%)$ & 8 (3.3 to 19.3$)$ & \\
\hline \multicolumn{6}{|l|}{ Leisure } \\
\hline No problems & 274 (91\%) & 203 (71\%) & 477 (81\%) & & $<0.001$ \\
\hline Uncertain ${ }^{\star \star}$ & $11(4 \%)$ & 52 (18\%) & $63(11 \%)$ & 2.4 (1.2 to 4.5$)$ & \\
\hline Problems & $16(5 \%)$ & $32(11 \%)$ & $48(8 \%)$ & 5.5 (2.8 to 10.9$)$ & \\
\hline
\end{tabular}

${ }^{*}$ From regression models adjusted for age and gender. Linear regression coefficients for MABC and KBIT, ORs for ADL difficulties.

†For adjusted group differences.

$\ddagger$ Group differences not tested because groups were divided on this basis.

$\S$ Tested with linear regression with age and sex as covariates.

१Test with logistic regression with rDCD status as the outcome and age and sex as covariates.

${ }^{* *}$ Uncertain refers to the fact that the assessor could not definitely ascertain from the parent's report that the child was having difficulty with a specific ADL.

ADL, Activities of daily living; DCD, Developmental coordination disorder; IQ, Intellectual ability; KBIT-2, Kaufman Brief Intelligence Test Second Edition; MABC-2, Movement Assessment Battery for Children - Second Edition; rDCD, At risk for DCD; TD, Typically developing.

to parent report, the majority of $\mathrm{rDCD}$ children do not experience significant impairments in ADLs. It is possible that difficulties will become more apparent as children age and daily activities become more motorically complex. However, this is also consistent with the population prevalence (2\% to $5 \%$ ): only a minority of children scoring below the $16^{\text {th }}$ percentile can be expected to meet clinical criteria. We also did not, for example, conduct clinical neurological examinations on these children; no medical diagnoses were made. These children are young; poor performance on motor testing may be within the bounds of normal variability in motor development. Although the reliability and validity of the MABC-2 have been reported to be good, some degree of measurement error is also unavoidable, and this will tend to attenuate measured associations. Nevertheless, because the study is longitudinal, it will be possible to continue to assess children in each of these diagnostic domains as they age.

We also observed most of the other expected correlates of low motor coordination. The preponderance of males is a consistent finding in work on almost all neurodevelopmental and behavioural conditions. ${ }^{5}$ We observed a clear sex difference in the prevalence of low motor coordination, with a male:female ratio of approximately 2:1. This difference broadly agrees with other general population samples, though it is much less marked than in some reports, which have occasionally reported ratios as high as 4.1 to $7: 1 .^{8}$

We also found that children in the rDCD group had poorer aerobic and musculoskeletal fitness than children in the TD group. Although we observed larger waist circumferences in children in the rDCD group than in 
Table 3 Group differences in health-related fitness and physical activity

\begin{tabular}{|c|c|c|c|c|c|}
\hline & TD & rDCD & Total & $\begin{array}{l}\text { Adjusted group } \\
\text { difference }(95 \% \mathrm{Cl})^{*}\end{array}$ & $\begin{array}{l}P \\
\text { valuet }\end{array}$ \\
\hline \multicolumn{6}{|l|}{ Body composition } \\
\hline BMI percentile & $54.3(27.2 ; n=301)$ & $58.0(27 ; n=287)$ & $56.1(27.2 ; n=588)$ & $3.7(-0.7$ to 8.1$)$ & 0.10 \\
\hline Waist circumference $(\mathrm{cm})$ & $53.8(3.4 ; n=301)$ & $54.4(4.1 ; n=287)$ & $54.1(3.8 ; n=588)$ & 0.7 (0.1 to 1.3$)$ & 0.02 \\
\hline \multicolumn{6}{|l|}{ Aerobic fitness } \\
\hline Total treadmill time (min) & $10.4(1.5 ; n=288)$ & $9.6(1.7 ; n=270)$ & $10.0(1.7 ; n=558)$ & $-0.76(-1.01$ to -0.51$)$ & $<0.001$ \\
\hline \multicolumn{6}{|l|}{ Muscular strength } \\
\hline Mean 30 s power $(W)$ & $70.9(24.6 ; n=297)$ & $56.9(27.9 ; n=274)$ & $64.2(27.1 ; n=571)$ & $-11.2(-14.7$ to -7.6$)$ & $<0.001$ \\
\hline \multicolumn{6}{|l|}{ Physical activity } \\
\hline MVPA (min per day) & $72.0(20.5 ; n=278)$ & $71.3(19 ; n=235)$ & $71.7(19.8 ; n=513)$ & $-2.6(-5.9$ to 0.7$)$ & 0.13 \\
\hline
\end{tabular}

${ }^{\star}$ From linear regression models adjusted for age and gender.

†For adjusted group differences.

BMI, Body mass index; DCD, Developmental coordination disorder; MVPA, Moderate to vigorous physical activity; rDCD, At risk for DCD; TD,

Typically developing.

children in the TD group, this difference was not clinically significant as waist circumferences differed by less than $1 \mathrm{~cm}$. In addition to no differences in BMI percentile nor daily MVPA observed, this suggests that body composition and physical activity are less affected by low motor coordination at younger ages. For a more detailed discussion of the fitness results, please see King-Dowling et al. ${ }^{12}$ Given that these differences have been consistently observed among older children with DCD, ${ }^{10}{ }^{189-41}$ it is likely that the differences in body composition will become more pronounced and physical activity will begin to appear as children age.

We observed few other demographic differences between groups. This may reflect the nature of our sample, which was relatively homogeneous: study participants were generally white and English speaking, and had higher average levels of education, and a relatively low proportion of families with low incomes. ${ }^{42}$ It also may reflect the age of our sample; some sociodemographic characteristics may come to influence motor coordination as children get older and the cost and time requirements of participation in organised sports and other activities increase. Nonetheless, the current evidence examining the association between demographic characteristics and motor coordination is inconsistent and multifaceted, varying by gender, age and skill domain ${ }^{434}$ and it is still unclear what role (if any) these factors play in motor development.

The recruitment process showed that the performance of our chosen screening instrument (DCDQ) was relatively poor vis-a-vis the MABC-2. This may be due, in part, to the young age of our sample, which may make parental identification of motor impairments difficult. A larger than expected proportion of screened children also scored below the $16^{\text {th }}$ percentile on the MABC-2. In the absence of other likely explanations, this is probably due to self-selection on the part of parents. CATCH was presented to families as a study of motor coordination, which may have drawn particular interest from parents who suspected their children might have poor functioning in this area.

\section{CONCLUSIONS}

Following the CATCH cohort over time will allow us to examine trajectories of motor coordination as children transition from early to middle childhood. Due to the relatively young age of the sample, we expect there will be some movement both into and out of the low motor coordination group. Examining the demographic, psychological and physical characteristics that are associated with this movement will be an important area for future investigation. Importantly, we will also be able to assess if parental reporting of their child's motor coordination and ADL difficulties becomes more prevalent/accurate as their expectations surrounding independence increases and daily tasks become more motorically demanding.

Acknowledgements The authors would like to thank all CATCH participants and their families for their valuable contribution to this study.

Collaborators Collaborations are welcome through specific research proposals which can be sent directly to the Principal Investigator (Dr. John Cairney). At present, there are no plans to make the data completely open access. Data collection is ongoing and will not be completed until 2019. After this, application to obtain specific data-cuts can be made directly to the Principal Investigator.

Contributors JC, SV and MCR prepared the original draft of the manuscript. SV conducted data analyses and put together tables and figures. MCR and SK-D led study implementation and were actively involved in study planning and data collection. MCR was responsible for the day-to-day project management. JC, CM, BT, TW, MYK and SV provided methodological input on various aspects of study design. DP provided input on clinical aspects of the study and was responsible for adjudication of study eligibility. All authors provided critical review of the manuscript for important intellectual content and approved the final version.

Funding This research was supported by project grant MOP-126015 from the Canadian Institutes of Health Research. The funders had no involvement in the study design; in the collection, analysis and interpretation of the data; in the writing of the report or in the decision to submit the paper for publication. 
Competing interests None declared.

Patient consent for publication Not required.

Ethics approval McMaster University (Hamilton Integrated Research Ethics Board). Provenance and peer review Not commissioned; externally peer reviewed. Data availability statement Data are available upon reasonable request.

Open access This is an open access article distributed in accordance with the Creative Commons Attribution Non Commercial (CC BY-NC 4.0) license, which permits others to distribute, remix, adapt, build upon this work non-commercially, and license their derivative works on different terms, provided the original work is properly cited, appropriate credit is given, any changes made indicated, and the use is non-commercial. See: http://creativecommons.org/licenses/by-nc/4.0/.

\section{REFERENCES}

1. Blank R, Smits-Engelsman B, Polatajko $\mathrm{H}$, et al. European Academy for Childhood Disability (EACD): Recommendations on the definition, diagnosis and intervention of developmental coordination disorder

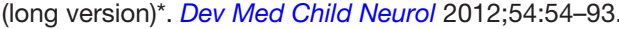

2. Missiuna C, Cairney J, Pollock N, et al. Psychological distress in children with developmental coordination disorder and attentiondeficit hyperactivity disorder. Res Dev Disabil 2014;35:1198-207.

3. Green D, Baird G, Barnett AL, et al. The severity and nature of motor impairment in Asperger's syndrome: a comparison with specific developmental disorder of motor function. J Child Psychol \& Psychiat 2002;43:655-68.

4. Green D, Charman T, Pickles A, et al. Impairment in movement skills of children with autistic spectrum disorders. Dev Med Child Neurol 2009;51:311-6.

5. American Psychiatric Association. Diagnostic and statistical manual of mental disorders. 5th edn. Arlington, VA: American Psychiatric Publishing, 2013.

6. Visser J. Developmental coordination disorder: a review of research on subtypes and comorbidities. Hum Mov Sci 2003;22:479-93.

7. Zwicker JG, Yoon SW, MacKay M, et al. Perinatal and neonatal predictors of developmental coordination disorder in very low birthweight children. Arch Dis Child 2013;98:118-22.

8. Kadesjö B, Gillberg C. Developmental coordination disorder in Swedish 7-year-old children. J Am Acad Child Adolesc Psychiatry 1999;38:820-8.

9. Missiuna C, Moll S, King S, et al. "Missed and misunderstood": Children with coordination difficulties in the school system. Int $J$ Spec Educ 2006;21:53-67.

10. Cairney J, Hay J, Veldhuizen S, et al. Trajectories of relative weight and waist circumference among children with and without developmental coordination disorder. Can Med Assoc J 2010;182:1167-72.

11. Cairney J, Hay JA, Faught BE, et al. Developmental coordination disorder and cardiorespiratory fitness in children. Pediatr Exerc Sci 2007:19:20-8.

12. King-Dowling S, Rodriguez C, Missiuna C, et al. Health-Related fitness in preschool children with and without motor delays. Med Sci Sports Exerc 2018:50:1442-8.

13. Cairney J, Hay JA, Veldhuizen S, et al. Developmental coordination disorder, sex, and activity deficit over time: a longitudinal analysis of participation trajectories in children with and without coordination difficulties. Dev Med Child Neurol 2010;52:e67-72.

14. Skinner RA, Piek JP. Psychosocial implications of poor motor coordination in children and adolescents. Hum Mov Sci 2001;20:73-94.

15. Poulsen AA, Ziviani JM, Cuskelly M. General self-concept and life satisfaction for boys with differing levels of physical coordination: the role of goal orientations and leisure participation. Hum Mov Sci 2006;25:839-60.

16. van den Heuvel M, Jansen DEMC, Reijneveld SA, et al. Identification of emotional and behavioral problems by teachers in children with developmental coordination disorder in the school community. Res Dev Disabil 2016;51-52:40-8.

17. Cairney J, Veldhuizen S. Is developmental coordination disorder a fundamental cause of inactivity and poor health-related fitness in children? Dev Med Child Neurol 2013;55(Suppl.):55-8.

18. Rivilis I, Hay J, Cairney J, et al. Physical activity and fitness in children with developmental coordination disorder: a systematic review. Res Dev Disabil 2011;32:894-910.
19. Hands B. Changes in motor skill and fitness measures among children with high and low motor competence: a five-year longitudinal study. J Sci Med Sport 2008;11:155-62.

20. Osika W, Montgomery SM. Physical control and coordination in childhood and adult obesity: longitudinal birth cohort study. BMJ 2008;337:a699-52.

21. Cairney J, Hay J, Veldhuizen S, et al. Trajectories of cardiorespiratory fitness in children with and without developmental coordination disorder: a longitudinal analysis. Br J Sports Med 2011;45:1196-201.

22. Coleman R, Piek JP, Livesey DJ. A longitudinal study of motor ability and kinaesthetic acuity in young children at risk of developmental coordination disorder. Hum Mov Sci 2001;20:95-110.

23. Kennedy-Behr A, Rodger S, Mickan S. A comparison of the play skills of preschool children with and without developmental coordination disorder. OTJR 2013;33:198-208.

24. King-Dowling S, Missiuna C, Rodriguez MC, et al. Reprint of "Cooccurring motor, language and emotional-behavioral problems in children 3-6 years of age". Hum Mov Sci 2015;42:344-51.

25. Schott N, Alof V, Hultsch D, et al. Physical fitness in children with developmental coordination disorder. Res Q Exerc Sport 2007;78:438-50.

26. Pless M, Carlsson M, Sundelin C, et al. Preschool children with developmental coordination disorder: a short-term follow-up of motor status at seven to eight years of age. Acta Paediatr 2002;91:521-8

27. Cairney J, Missiuna C, Timmons BW, et al. The coordination and activity tracking in children (catch) study: rationale and design. BMC Public Health 2015;15:1266.

28. Henderson SE, Sugden DA BAL. Movement Assessment Battery for Children Examiner's Manuel. 2nd edn. London, UK: Harcourt Assessment, 2007.

29. Ellinoudis T, Evaggelinou C, Kourtessis T, et al. Reliability and validity of age band 1 of the Movement Assessment Battery for Children-second edition. Res Dev Disabil 2011;32:1046-51.

30. Kaufman AS, Kaufman NL. Kaufman brief intelligence test. 2nd edn. Circle Pines, MN: AGS Publishing, 2004.

31. Missiuna C, Gaines R, Soucie H. Why every office needs a tennis ball: a new approach to assessing the clumsy child. Can Med Assoc J 2006;175:471-3.

32. Missiuna C, Pollock N, Egan M, et al. Enabling occupation through facilitating the diagnosis of developmental coordination disorder. Can $J$ Occup Ther 2008;75:26-34

33. Kuczmarski RJ, Ogden CL, Guo SS, et al. Cdc growth charts for the United States: methods and development. Vital Health Stat 2000;(246):1-190.

34. Wang J, Thornton JC, Bari S, et al. Comparisons of waist circumferences measured at 4 sites. Am J Clin Nutr 2003;77:379-84.

35. Bruce RA, Kusumi F, Hosmer D. Maximal oxygen intake and nomographic assessment of functional aerobic impairment in cardiovascular disease. Am Heart J 1973;85:546-62.

36. Bar-Or O. The Wingate anaerobic test. Sports Medicine 1987;4:381-94.

37. Evenson KR, Catellier DJ, Gill K, et al. Calibration of two objective measures of physical activity for children. J Sports Sci 2008;26:1557-65.

38. Wilson BN, Crawford SG, Green D, et al. Psychometric properties of the revised developmental coordination disorder questionnaire. Phys Occup Ther Pediatr 2009;29:182-202.

39. Cairney J, Veldhuizen S, King-Dowling S, et al. Tracking cardiorespiratory fitness and physical activity in children with and without motor coordination problems. J Sci Med Sport 2017;20:380-5.

40. Hendrix CG, Prins MR, Dekkers H. Developmental coordination disorder and overweight and obesity in children: a systematic review. Obes Rev 2014;15:408-23.

41. Joshi D, Missiuna C, Hanna S, et al. Reprint of "Relationship between BMI, waist circumference, physical activity and probable developmental coordination disorder over time". Hum Mov Sci 2015:42:307-17.

42. Statistics Canada. Canada's Educational Portrait Census of Population, 2016. Available: www150.statcan.gc.ca/n1/pub/11-627m/11-627-m2017036-eng.htm [Accessed 14 Dec 2018].

43. Barnett LM, Lai SK, Veldman SLC, et al. Correlates of gross motor competence in children and adolescents: a systematic review and meta-analysis. Sports Med 2016;46:1663-88.

44. Hardy LL, Reinten-Reynolds T, Espinel P, et al. Prevalence and correlates of low fundamental movement skill competency in children. Pediatrics 2012;130:e390-8. 